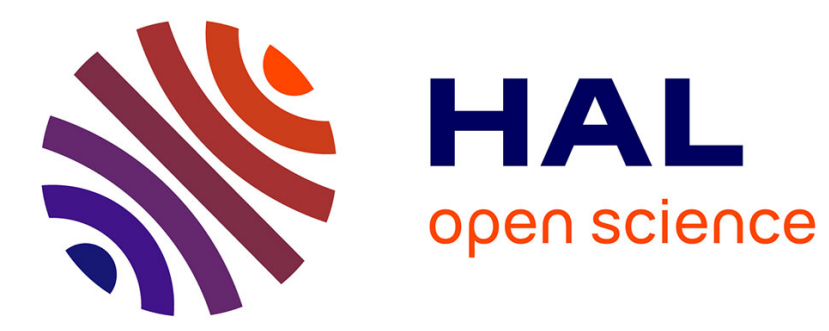

\title{
Optical and Electrical Characterization of Creeping Discharges over Solid/Liquid Interfaces under Lightning Impulse Voltage
}

Lazhar Kebbabi, Abderrahmane Beroual

\section{- To cite this version:}

Lazhar Kebbabi, Abderrahmane Beroual. Optical and Electrical Characterization of Creeping Discharges over Solid/Liquid Interfaces under Lightning Impulse Voltage. IEEE Transactions on Dielectrics and Electrical Insulation, 2006, 13 (3), pp.565-571. hal-00135202

\author{
HAL Id: hal-00135202 \\ https://hal.science/hal-00135202
}

Submitted on 7 Mar 2007

HAL is a multi-disciplinary open access archive for the deposit and dissemination of scientific research documents, whether they are published or not. The documents may come from teaching and research institutions in France or abroad, or from public or private research centers.
L'archive ouverte pluridisciplinaire HAL, est destinée au dépôt et à la diffusion de documents scientifiques de niveau recherche, publiés ou non, émanant des établissements d'enseignement et de recherche français ou étrangers, des laboratoires publics ou privés. 


\title{
Optical and Electrical Characterization of Creeping Discharges over Solid/Liquid Interfaces under Lightning Impulse Voltage
}

\author{
L. Kebbabi and A. Beroual \\ Ecole Centrale de Lyon \\ Centre de Génie Electrique de Lyon \\ CNRS UMR 5005, Ecully, France
}

\begin{abstract}
This paper deals with the experimental characterization of discharges propagating over solid insulators immersed in mineral oil, under impulse voltages using a point-plane electrode arrangement. It's shown that the nature and the thickness of the solid insulator significantly influence the characteristics of creepage discharge and especially the final length $L_{f}$ and the density of branches $\rho$. For a given thickness, $L_{f}$ increases quasi-linearly with the voltage; it decreases when the thickness increases. So $\rho$ increases with the dielectric constant of the solid insulator; it also increases when the thickness is reduced. This indicates the important role of the capacitive effect in the propagation mechanism. The main discharge is followed by a secondary one of opposite sign to that of the main discharge.
\end{abstract}

Index Terms - Creepage discharge, propagation, interface phenomena, breakdown.

\section{INTRODUCTION}

THE solid/liquid insulating structures are present in various high voltage applications and especially in high voltage oil filled apparatus such as power transformers and capacitors, circuitbreakers, cables. The use of such structures enables to increase the dielectric strength of the system. And as any insulation, these structures are exposed to different stresses and particularly to the discharge phenomena. The propagation of discharges at the solid/liquid interface or within the bulk of the solid or the liquid can lead to the failure of the system. Thus, the knowledge of the initiation conditions of these discharges and the parameters characterizing their propagation up to flashover is of a great interest for the dimensioning and optimization of high voltage apparatus. This enables indeed to know the initiation voltage of surface discharges and to choose the kind and dimensions of the constituents of insulating structure. Numerous studies have been devoted to the length and the shape of the creepage discharges [16]. Thus, it was reported that these discharges generally consist of radial ramified filamentary patterns resembling Lichtenberg figures.

This paper is aimed at the experimental characterization of discharges propagating at solid/liquid interfaces under impulse voltages using a point-plane electrode arrangement. We first describe the general aspect of the creepage discharge and the corresponding current depending on the polarity of the voltage.

Manuscript received on 12 September 2005, in final form 23 January 2006.
Then we analyze the influence of the thickness and the kind of the solid insulator on both the final length and the density of branches.

\section{EXPERIMENTAL SET-UP}

The diagram of the experimental arrangement is given in Figure 1. It is similar to that we used in previous work [1]. The test cell containing the considered insulating structure (liquid/solid) and a point-plane electrode arrangement consists of a cylindrical core of $90 \mathrm{~mm}$ high and $110 \mathrm{~mm}$ inner diameter, and two flats and circular covers; the upper cover was of Plexiglas (transparent material) enabling to visualize the discharges and to support the sharp electrode; the lower one which constitutes also the electrode plane, was of brass. The point electrode was made of tungsten the radius tip of which is $10 \mu \mathrm{m}$. The cylindrical core of the test cell consists of two screwed parts: an upper part of $60 \mathrm{~mm}$ high made of Teflon and a bottom part issued from Plexiglas of $30 \mathrm{~mm}$ high. The contact between the point electrode and the solid samples is controlled by a CDD camera through the transparent part of the cylindrical core of the test cell. The solid insulating samples we inserted between the electrodes are discs of $100 \mathrm{~mm}$ diameter; their thickness varies between 2 and $30 \mathrm{~mm}$. The solid insulating samples we tested are issued from different materials namely Phenoplast resin (known as bakelite), glass and polycarbonate. These samples are immersed in mineral oil (naphtenic type) which is filtered and degassed after each 
flashover. The oil and solid samples are changed each time, we observe a flashover or traces on the solid surface.

The tests are achieved under lightning impulse voltage $(1.2 / 50$ $\mu \mathrm{s})$ supplied by a $200 \mathrm{kV}$ Marx generator.

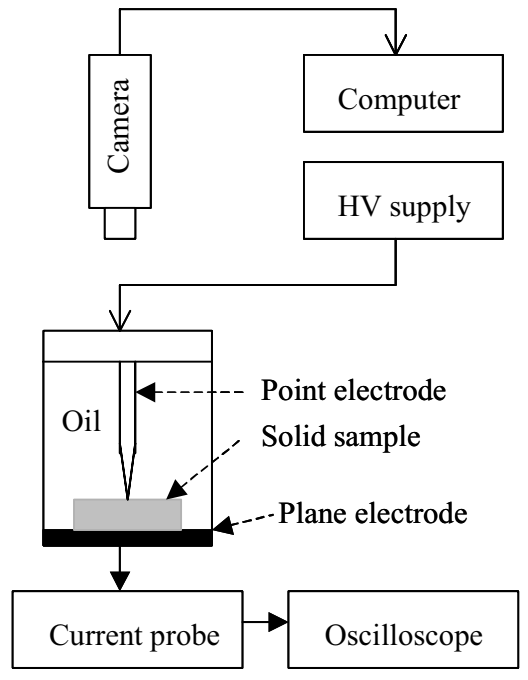

Figure 1. Scheme of the experimental setup.

The optical observation of the discharges is based on the integrated images taken with the help of a CDD camera connected to a high performance video card. The CDD camera is a "SONY XC-HR58" type, high SVGA resolution (767x580 pixels) image capturing at a speed of 50 full frames/sec. It's set to record 900 images before stopping. During the image grab, the impulse voltage is applied. And thanks to the CDD camera and the video card to which it's connected, we get the image of the discharge in its maximum extension.

The currents associated to the discharges are measured through a $50 \Omega$ non-inductive resistor connected in series with the test cell, and thanks to a high time resolution oscilloscope (Tektronix DSA 601A). The electrical charge is obtained by the integration of the current; this integration is automatically achieved by the oscilloscope.

\section{DISCHARGES MORPHOLOGY}

\subsection{GENERAL SHAPE}

Figures 2 and 3 show the influence of the polarity of the voltage on the shape of discharges propagating over an oil/bakelite interface. The discharges emanating from a negative point are radial with straight branches. The end of these branches and their ramifications constitutes a more or less circular contour, centered at the point.

Contrary to the negative discharges, the positive ones are characterized by ramified branches ended by very luminous points at their extremities. They do not present a radial shape as observed with the negative discharges.

Note that for a given solid sample, if the discharges leave traces on the surface of this insulator (Figure 4), some branches of the following discharges go alone these traces (Figure 5). For that purpose, the oil and solid samples are changed each time traces are observed.

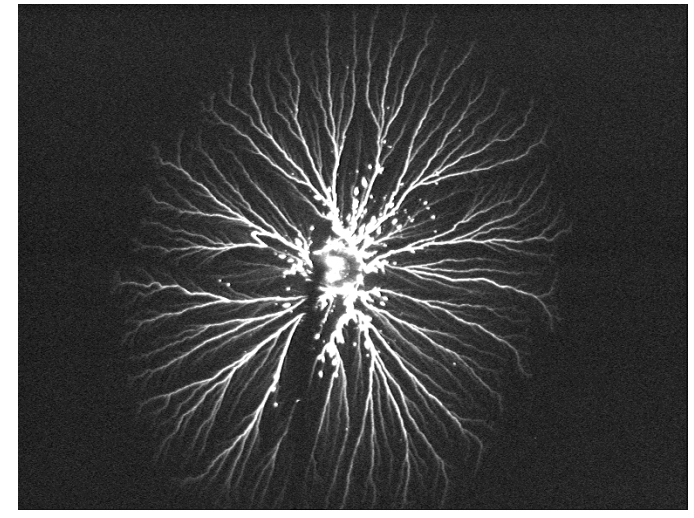

Figure 2. Photographs of negative creeping discharges over a bakelite sample, under negative impulse voltage $\mathrm{U}=-50 \mathrm{kV}$.

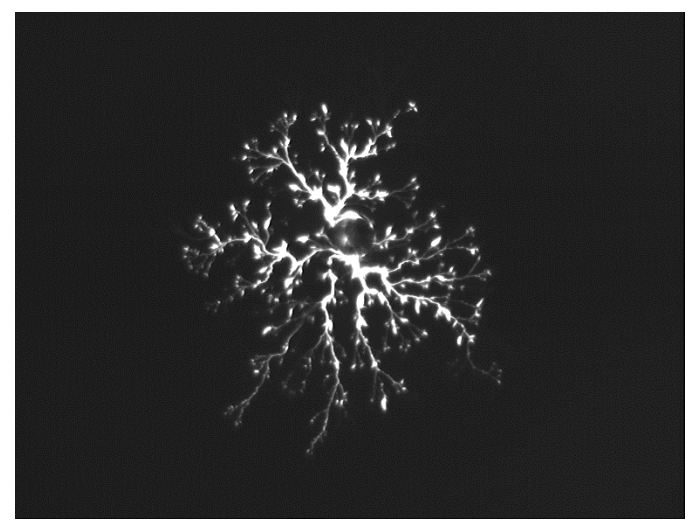

Figure 3. Photographs of positive creeping discharges over a bakelite sample, under positive impulse voltage $\mathrm{U}=+40 \mathrm{kV}$.

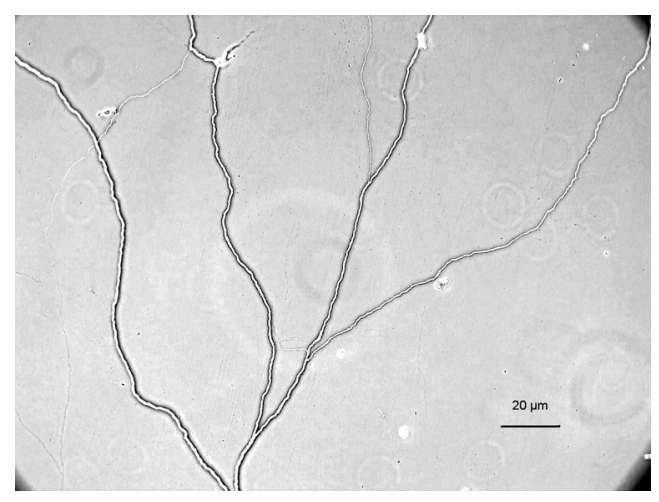

Figure 4. Photograph of traces left by negative creeping discharges over a glass sample of $5 \mathrm{~mm}$ thickness.

\subsection{FINAL LENGTH}

The thickness and the nature of the solid insulating sample significantly influence the final length $L_{f}$ of discharges as shown in Figure 6. $L_{f}$ increases linearly with the applied voltage $U$ whatever the solid sample. And for a given voltage, $L_{f}$ is higher with Phenoplast resin and Glass samples than with Polycarbonate samples. Moreover, the thinner the solid sample, the longer $L_{f}$ is. 


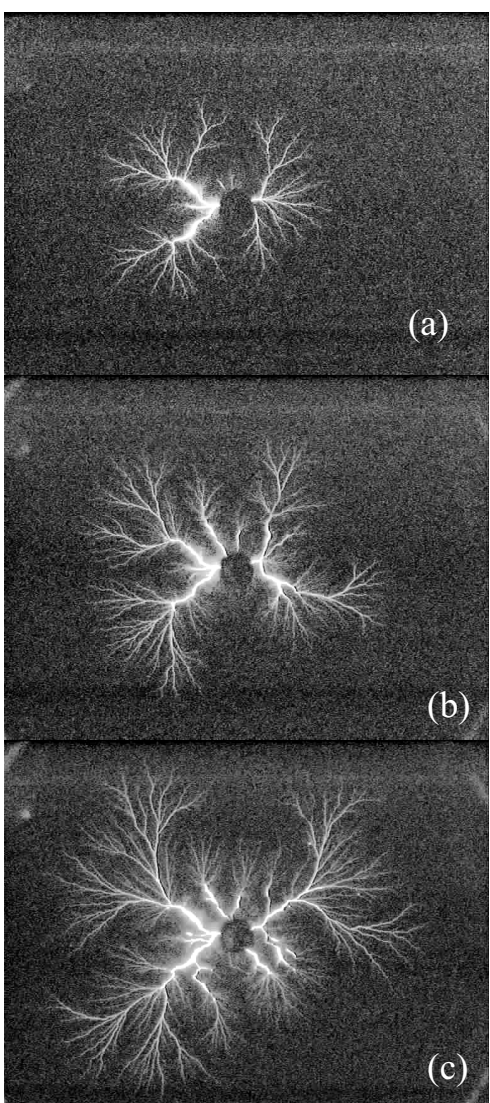

Figure 5. Photographs of negative creeping discharges over a surface of glass sample on which there were discharge traces: (a) $35 \mathrm{kV}$, (b) $40 \mathrm{kV}$ and (c) 45 $\mathrm{kV}$. The thickness of the solid sample is $5 \mathrm{~mm}$.

On the other hand, the initiation threshold voltage of discharges, $U_{s}$, depends upon the type of solid samples ; the measurement of $U_{s}$ is based on the detection of the first current pulse. $U_{s}$ is higher with polycarbonate $\left(\varepsilon_{r}=2.9, \varepsilon_{r}\right.$ being the relative permittivity) than with Phenoplast resin $\left(\varepsilon_{r}=4.8\right)$ and Glass $\left(\varepsilon_{r}=5\right)$ which have a highest relative permittivity (Table 1). This is due to the electric field strength at the tip of the point electrode which is all the more important as the difference of the permittivity between the solid insulating sample and transformer oil $\left(\varepsilon_{r}=2.3\right)$ is high. This can be verified thanks to a simple simulation with FLUX2D package which uses finite elements [7]. Figure 7 gives an example of such a simulation.

\subsection{DENSITY OF BRANCHES}

The density of branches also depends on the type of solid insulating and its thickness. Figure 8 shows photographs of creeping discharges propagating over Bakelite samples of various thicknesses, immersed in mineral oil, under negative impulse voltage. Note that these discharges are of the same final length $\left(L_{s}=45 \mathrm{~mm}\right)$; they are obtained with different voltage. For each oil/solid insulating interface, the surface density of branches increases when the thickness of solid insulating is reduced and/or the dielectric constant of the solid insulator is increased, indicating the possible implication of capacitive effects in the discharge propagation mechanism.
Table 1. Threshold voltage of negative discharge inception.

\begin{tabular}{c|cccc}
\hline \hline \multirow{2}{*}{ Thickness } & \multicolumn{4}{|c}{ Generation voltage Us $(\mathrm{kV})$} \\
& \multicolumn{4}{|c}{} \\
\cline { 2 - 5 } & Bakelite & Glass & PC & Oil volume \\
\hline $5 \mathrm{~mm}$ & $10 \pm 2$ & $10 \pm 2$ & $14 \pm 2$ & $18 \pm 2$ \\
$10 \mathrm{~mm}$ & $11 \pm 2$ & $11 \pm 2$ & $15 \pm 2$ & $20 \pm 2$ \\
$15 \mathrm{~mm}$ & $12 \pm 2$ & $12 \pm 2$ & $17 \pm 2$ & $21 \pm 2$ \\
$20 \mathrm{~mm}$ & $13 \pm 2$ & $13 \pm 2$ & $21 \pm 2$ & $26 \pm 2$ \\
\hline \hline
\end{tabular}
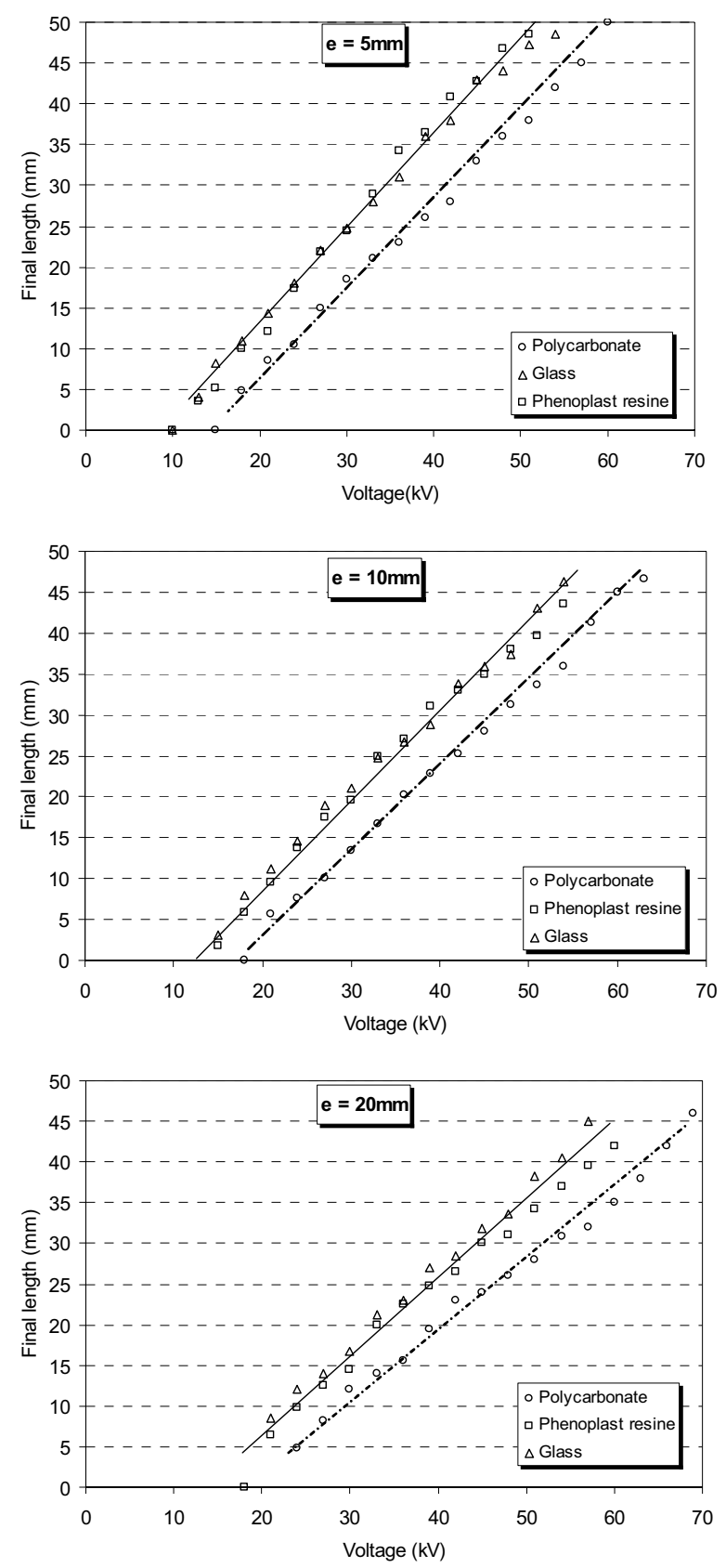

Figure 6a. Final length $\mathrm{L}_{\mathrm{f}}$ of the creepage discharge propagating over the three investigated solid samples versus the crest value of the applied voltage for different thicknesses. The voltage is a negative lightning impulse voltage $(1.2 / 50 \mu \mathrm{s})$ 
In order to analyse the density of branches, we choose discharges of a given final length we called "standard length" $L_{s}$ for all solid insulating samples. Thus, for each sample we increase gradually the voltage until we obtain a discharge of a final length equal to $L_{s}$. Note that the voltage required to get a final length of discharges equal to a given $L_{s}$ is higher for phenoplast resin than for glass and for polycarbonate, respectively.
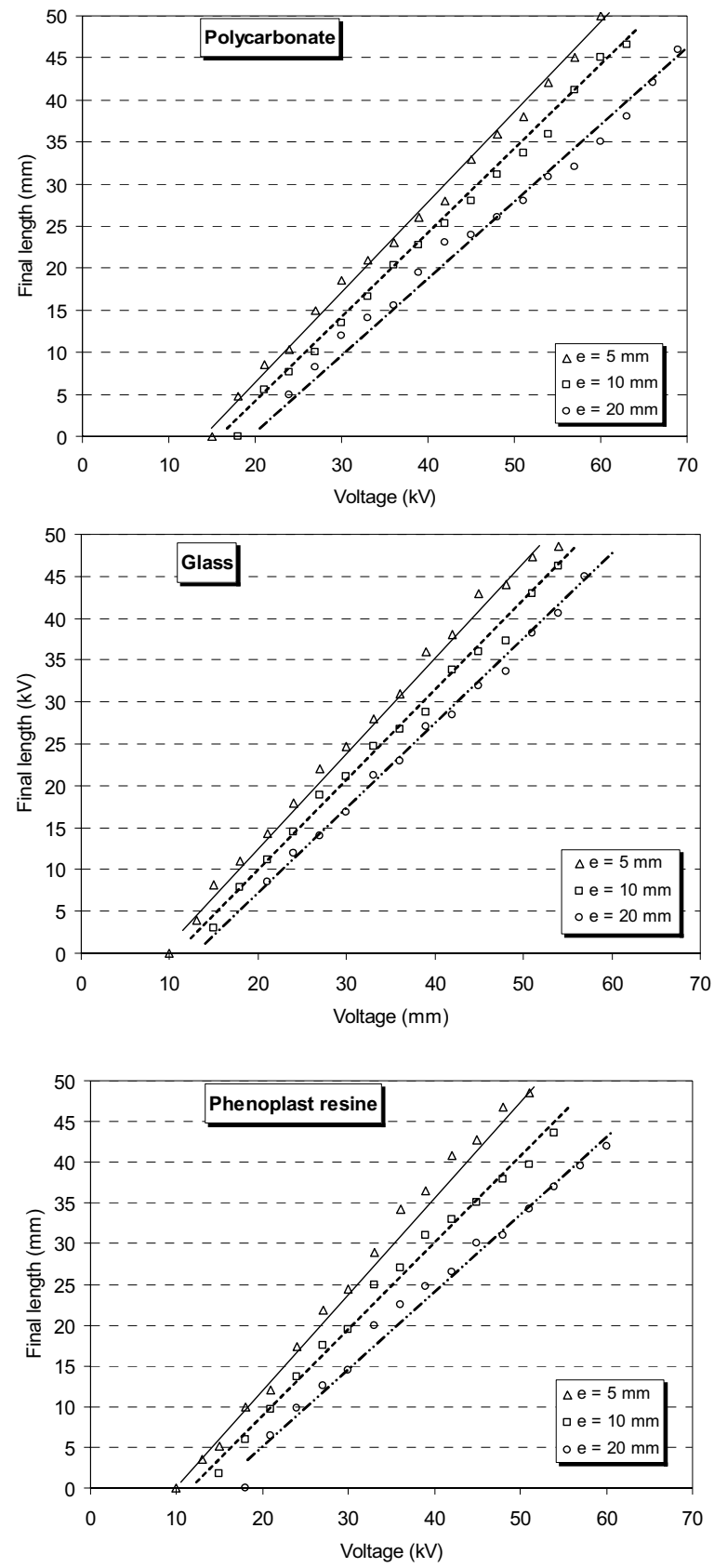

Figure 6b. Final length $\mathrm{L}_{\mathrm{f}}$ of the creepage discharge propagating over each type of solid samples versus the crest value of the applied voltage for different thicknesses. The voltage is a negative lightning impulse voltage $(1.2 / 50 \mu \mathrm{s})$.

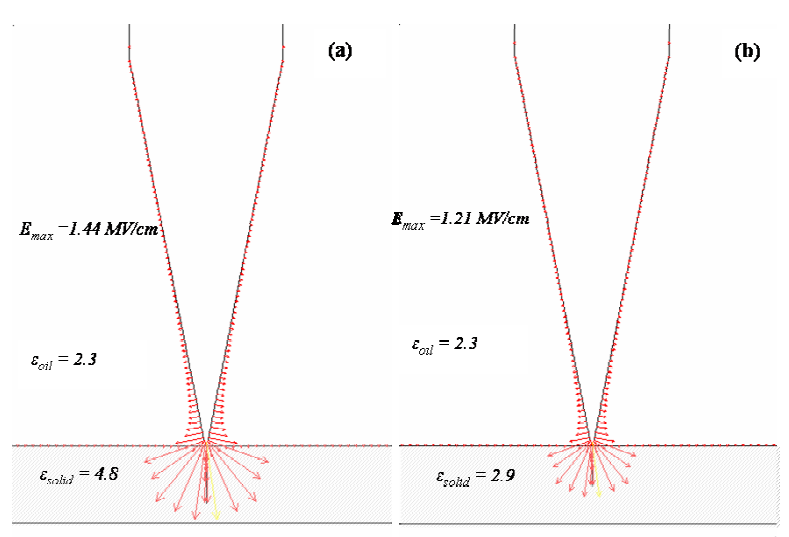

Figure 7. Example of electric field distribution obtained using FLUX2D package for structures consisting of solid samples of bakelite and polycarbonate immersed in mineral oil, for a voltage $U_{\text {crest }}=10 \mathrm{kV}$ and a solid thickness $\mathrm{e}=2 \mathrm{~mm}$.

To compute the radial density of branches, we conceived a specific software we described in details in a previous work [8]. This program produces concentric virtual circles of an ascending radius, centered at the reference point. The number of branches intersecting the circles is counted, and the radial density of branches $\rho(r)$ is deduced. The total length $L_{T}$ of all the branches constituting the discharge is also calculated. Thus we observe that, for each oil/solid insulating interface, $\rho$ increases when the thickness of the solid insulating is reduced. On the other hand, the density of branches does not vary with the radius $r$, and the mean radial density of branches is quasiconstant for each material and thickness. The results obtained with negative impulse voltages are summarized in Table 2. The main result is that $\rho$ decreases when the thickness of solid sample increases.

Table 2. Mean Radial density of branches of negative discharges.

\begin{tabular}{c|ccc}
\hline \hline $\begin{array}{c}\text { Thickness of } \\
\text { insulation } \\
\text { samples }\end{array}$ & \multicolumn{3}{|c}{$\begin{array}{c}\text { Mean radial density of branches } \\
\text { (number of branches/cm) }\end{array}$} \\
\cline { 2 - 4 } $2 \mathrm{~mm}$ & $3,4 \pm 0,2$ & $3.3 \pm 0,2$ & Plexiglas \\
\hline $10 \mathrm{~mm}$ & $2,5 \pm 0,2$ & $2,4 \pm 2$ & $2,6 \pm 0,2$ \\
$20 \mathrm{~mm}$ & $1,8 \pm 0,2$ & $1,6 \pm 0,2$ & $1,3 \pm 0,2$ \\
$30 \mathrm{~mm}$ & $1,5 \pm 0,2$ & $1,4 \pm 0,2$ & $1,1 \pm 0,2$ \\
\hline \hline
\end{tabular}

\section{CURRENT}

Figure 9 shows the current waveform accompanying the creeping discharge when the point is positive. This current consists of a continuous component on which are superimposed discrete pulses. The amplitude of these currents increases with the voltage. The current associated to the creeping discharge when the point is negative consists of discrete pulses of a very high frequency (Figures 10) at low voltages. When the voltage is increased, a continuous component appears. Such current shapes were observed in liquids alone [3]. 


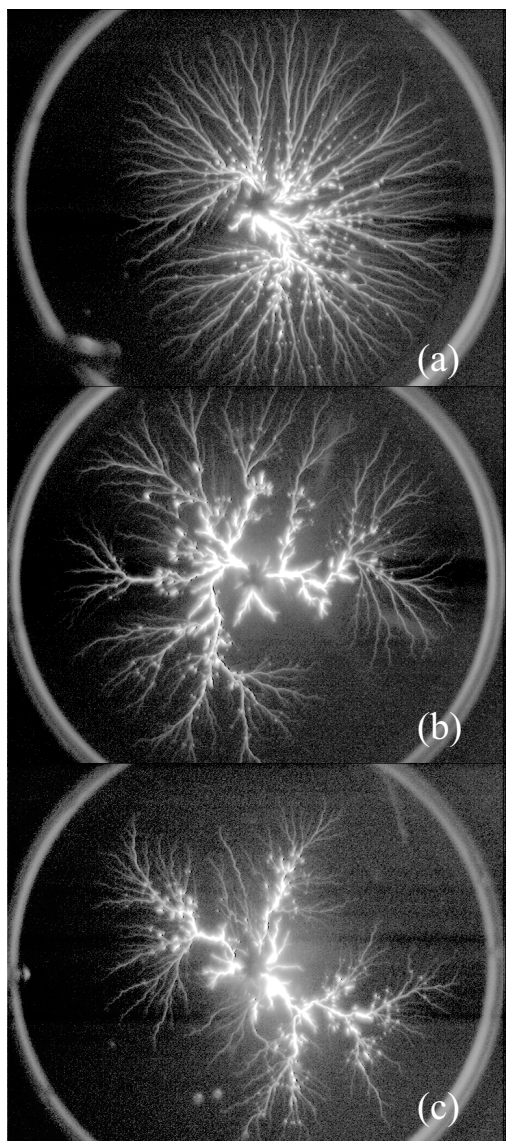

Figure 8. Photographs of creeping discharges of the same length propagating over Bakelite samples of various thicknesses, immersed in mineral oil, under negative lightning impulse voltage: (a) $2 \mathrm{~mm}$, Ucrest $=47 \mathrm{kV}$, (b) $10 \mathrm{~mm}$, Ucrest $=54 \mathrm{kV}$ and (c) $20 \mathrm{~mm}$, Ucrest $=62 \mathrm{kV}$.

The current waveforms examined on a large time scale show the existence of a weak secondary discharge occurring at approximately $100 \mu \mathrm{s}$ after the extinction of the main discharge, for both polarities (Figures 11 and 12). The sign of the current associated to the secondary discharge is the opposite to that of the applied voltage; it is negative when $U$ is positive and vice versa. This is likely due to the space charge deposited by the discharge when propagating over the solid insulating surface and the electric field it induced.

\section{CHARGE}

For the three considered solid materials, the measured total electrical charge $Q_{m}$ increases with the applied voltage (Figures 13-15). On the other hand, for the same applied voltage, $Q_{m}$ increases with the dielectric constant of the solid sample. Indeed, $Q_{m}$ is higher with Phenoplast resin and Glass samples than with Polycarbonate ones. As the final length and the branches density of discharges, $Q_{m}$ increases when the thickness of the solid insulating samples decreases.

To estimate the electrical charge associated to creeping discharges, Atten and Saker [2] proposed a model of a single streamer propagating over oil/glass interface using parallel wire-plane capacitor. They assumed that the streamer channel is at a constant potential $U$; the radius of the channel $r_{c}$ was also considered to be constant. According to these authors, the total charge $Q_{s}$ is given by

$$
Q_{s}=g \frac{2 \pi \varepsilon_{0} \varepsilon_{r}}{\ln \left(2 e / r_{c}\right)} U x_{m}
$$

where $e$ is the thickness of the solid insulator ; $x_{m}$ is the length of the streamer; $g$ is a constant reflecting the influence of the surrounding of the channel $(g \leq 1)$.

Due to the radial structure of the negative creeping discharges, we can extend the above relationship (related to a single streamer) to the whole discharge since we can measure the total length $L_{T}$ of all its branches (see section 3.3). Thus by taking $g=1$, the total charge of a negative creeping discharge will be

$$
Q_{T}=\frac{2 \pi \varepsilon_{0} \varepsilon_{r}}{\ln \left(2 e / r_{c}\right)} U L_{T}
$$

where $e$ is the thickness of the solid insulator and $r_{c}$ is the radius of the channel; in our calculation, we set $r_{c}=10 \mu \mathrm{m}$ which is an average value of that reported in literature [2].

By plotting $Q_{T}$ for the three considered solid materials and two thicknesses and by taking the average value between the crest voltage and the voltage at the time $t_{p}$ corresponding to the current extinction $(\mathrm{I}=0)$, we observe a reasonable accordance between the simulated results and the experimental ones (Figures 13-15). In fact, the voltage is not constant and one has to take into account the real shape of the voltage. It appears however, from our experiment that the voltage drop doesn't exceed $25 \%$ with respect to a crest value.

Therefore, by taking a voltage constant (i.e., the average voltage) in our simulation, we have a value of $Q_{T}$ with a maximum dubiousness of about $12.5 \%$ which we represented on the figures. Therefore, the extension of the model proposed for a single streamer branch [2] and its adaptation to the whole discharge works well.

\section{CONCLUSION}

In this work we showed that the smaller the thickness of the solid insulating sample, the more branched are the discharge structures. The radial density of branches $\rho(r)$ increases when the thickness of the insulator is reduced. On the other hand, the amplitude and shape of the measured currents remind those observed in large gaps of transformer oils. The current record in relative long time scale shows the occurrence of a secondary discharge of an opposite polarity to that of the applied voltage. This is likely due to the space charge deposited at the solid insulating surface when the discharge propagates, resulting in a modification of the electric field. The total charge of the creeping discharge calculated using a simplified model (parallel wire-plane capacitor) is in a good accordance with that measured experimentally. 


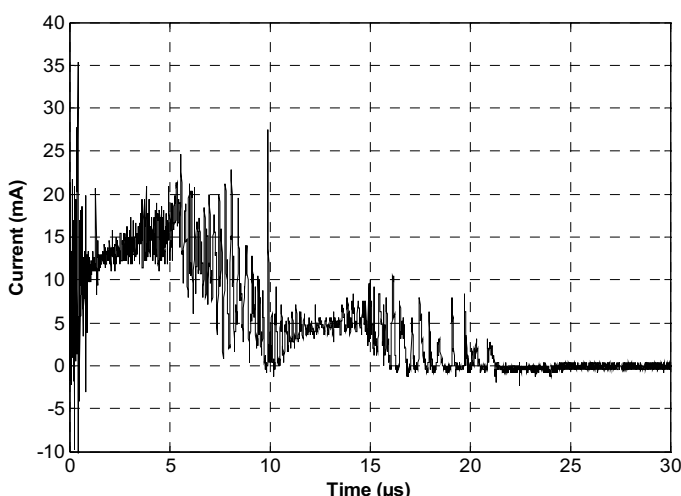

Figure 9. Current waveform of creepage discharge propagating over a bakelite/oil interface under positive impulse voltage $U_{\text {crest }}=+22 \mathrm{kV}$.

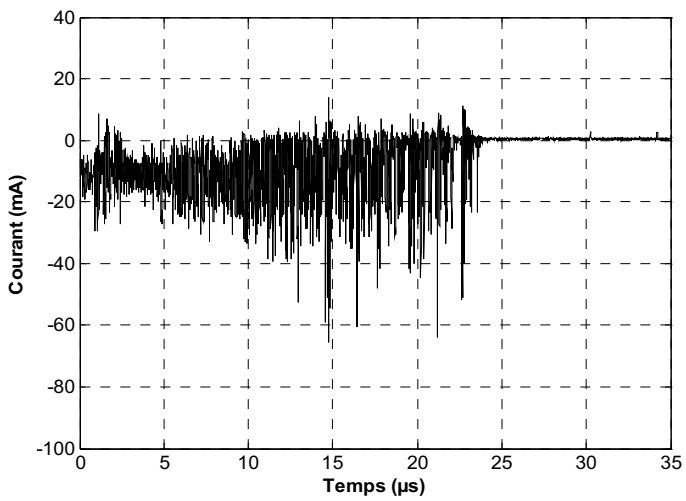

Figure 10. Current waveform of creepage discharge propagating over a bakelite/oil interface under negative impulse voltage $U_{\text {crest }}=-22 \mathrm{kV}$.

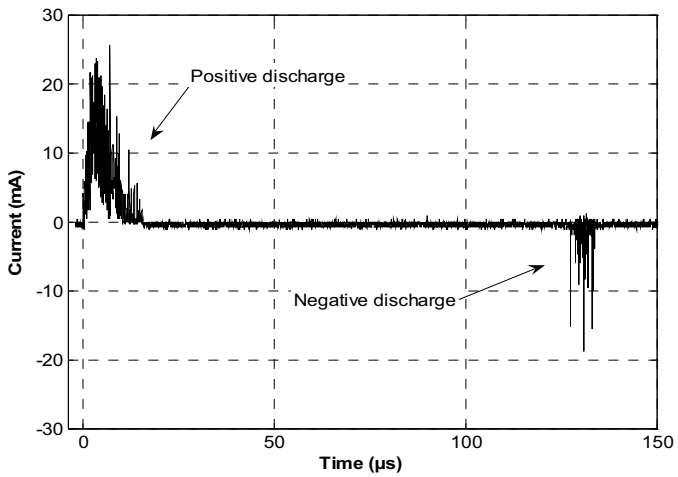

Figure 11. Current record in large time scale of positive discharge, taken under positive lightning impulse voltage $(1.2 / 50 \mu \mathrm{s})$ of $28 \mathrm{kV}$ magnitude. The main positive discharge is followed by a secondary negative one.

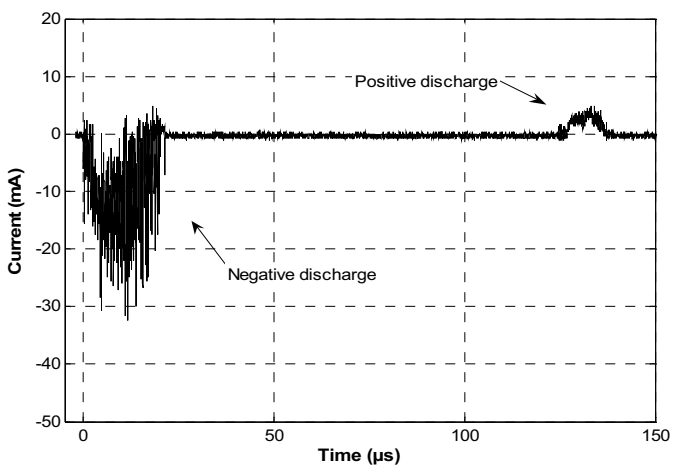

Figure 12. Current record in large time scale of negative discharge under negative lightning impulse voltage $(1.2 / 50 \mu \mathrm{s})$ of $-28 \mathrm{kV}$ magnitude. The main negative discharge is folowed by a secondary positive one.

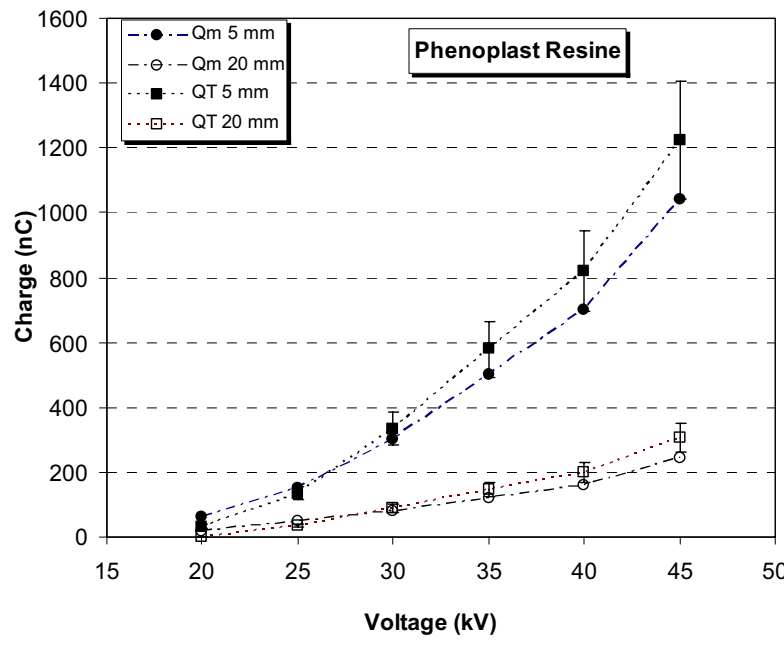

Figure 13. Total charge versus the applied voltage, obtained with Phenoplast resin samples of 5 and $20 \mathrm{~mm}$ thicknesses under negative polarity. $Q_{m}$ experimental values and $Q_{T}$ : calculated values using equation (2).

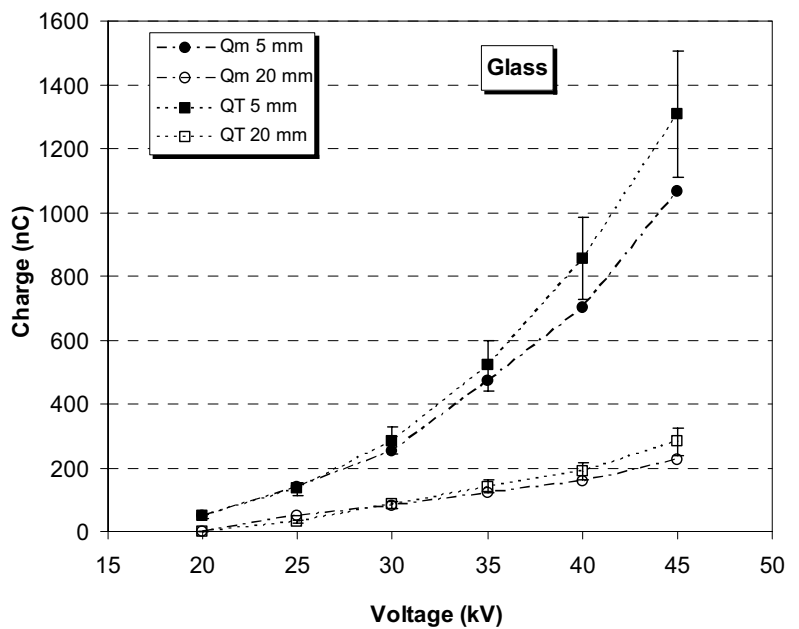

Figure 14. Total charge versus the applied voltage, obtained with Glass samples of 5 and $20 \mathrm{~mm}$ thicknesses under negative polarity. $Q_{m}$ : experimental values and $Q_{T}$ : calculated values using equation (2).

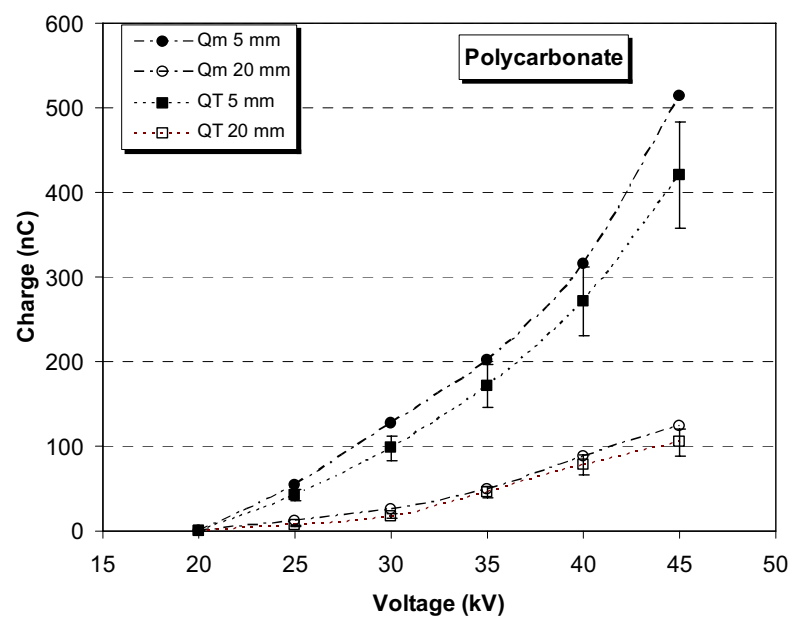

Figure 15. Total charge versus the applied voltage, obtained with Polycarbonate samples of 5 and $20 \mathrm{~mm}$ thicknesses under negative polarity. $Q_{m}$ : experimental values and $Q_{T}$ : calculated values using equation (2). 


\section{RefERENCES}

[1] L. Kebbabi and A. Beroual. "Influence of the properties of materials and the hydrostatic pressure on creepage discharge characteristics over solid/liquid interfaces", IEEE Conf. Electr. Insul. Dielectr. Phenomena (CEIDP), Albuquerque, New Mexico, USA, pp.293-296, 2003.

[2] P. Atten and A. Saker, "Streamer propagation over a liquid/solid interface", IEEE Trans. Electr. Insul., Vol. 28, pp. 230-242, 1993.

[3] A. Beroual, M. Zahn, A. Badent, K. Kist, A.J. Schwabe, H. Yamashita K. Yamazawa, M. Danikas, W.G. Chadband, Y. Torshin, "Propagation and Structure of Streamers in Liquid Dielectrics", IEEE Electr. Insul. Mag., Vol. 14, No. 2, pp.6-17, 1998.

[4] J. C . Devins and S. J. Rzad, "Streamer Propagation in Liquids and over Liquid-Solid Interfaces", IEEE Conf. Electr. Insul. Dielectr. Phenomena (CEIDP), pp.383-394, 1982.

[5] Y. Nakao, M. Naruse,H. Itoh, Y. Suzuki, Y. Sakai and H. Tagashira, "Influence of a Sort and a Thickness of Solid Insulators on the Propagation of the Positive Creepage Discharge in Transformer Oil", Trans. IEE Japan, Vol. 116-4, No. 10, pp.849-854, 1996.

[6] R.Hanaoka, T.Kohrin, T.Miyagawa and T.Nishi, "Creepage discharge characteristics over solid-liquid interfaces with grounded side electrode", IEEE Trans. Dielectr. Electr. Insul., Vol. 9, pp.308-315, 2002

[7] MAGSOFT Corporation, FLUX2D User Guide, MAGSOFT- CEDRAT, Troy, New York, 1995.

[8] L. Kebbabi and A. Beroual, "Influence of solid insulating thickness on the morophology of creeping discharges propagating over solid/liquid interfaces - Fractal analysis", J. of Physics D: Appl. Phys., Vol. 39, pp.177-183, 2005 .

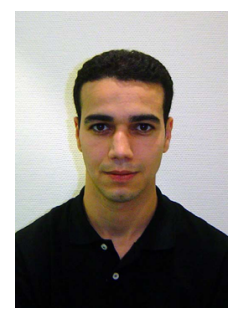

Lazhar Kebbabi was born in 1975 in Constantine, Algeria. He received the Dipl. Ing. and M.S. in electrical engineering, respectively in 2001 from the University of Constantine, Algeria, and in 2002 from Ecole Centrale de Lyon, France. He presently works as a Ph.D. student at Ecole Centrale de Lyon in the field of high voltage and dielectric materials.

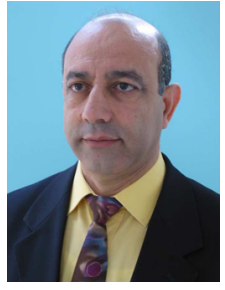

Abderrahmane Beroual (M'92) was born on 30 October 1951. He received the Dipl. Ing. and the Ph.D degrees in electrical engineering, respectively in 1976 from the Ecole Nationale Polytechnique of Algiers, Algeria and in 1979 from the Technical University of Wroclaw, Poland. In 1987, he obtained the Doctorat d'Etat ès Sciences Physiques degree from the Institut National Polytechnique of Grenoble, France. In 1980, he joined the Department of Electrical Engineering at the Ecole Nationale Polytechnique of Algiers. From 1983 to 1987, he was a researcher at the Laboratoire d'Electrostatique et de Matériaux Diélectriques (LEMD) - CNRS of Grenoble, France and associate professor at the Joseph Fourier University of Grenoble. He received the title of professor at the Ecole Nationale Polytechnique of Algiers in 1987. In 1989, he joined the Ecole Centrale de Lyon, France where he is presently professor and the head of the Dielectric Materials and High Voltage team at the Centre de Génie Electrique de Lyon (CEGELY) - CNRS as well as responsible for the Master Research Program in Electrical Engineering. He is responsible for numerous research projects. His main research interests include high voltage insulating, dielectric materials, outdoor insulation, long air discharge and lightning, modeling of discharges and composites. He is author/co-author of more than 230 papers and four patents. He supervised about $30 \mathrm{Ph} . \mathrm{D}$. theses. He was the leader of the International Study Group on Streamer Propagation in Liquids of the IEEE - DEIS (1994 - 1998). He is on the International Advisory Committees of the International Conference on Dielectric Liquids and the International Conference on Advances in Processing, Testing and Application of Dielectric Materials. 